eye, continue to be a target in boxing and should we advise boxers with previous retinal detachments to give up boxing?

In a survey $58 \%$ of boxers were found to have sustained injuries that threatened their vision. ${ }^{2}$ Few other situations exist in which there is such a strong relation between cause and effect. Though the link between smoking and heart disease is more tenuous, it does not prevent doctors from advising their patients against smoking. Why do we not advise against boxing?

There is as yet no evidence that a boxer with a previous retinal detachment is more likely to develop a new detachment than any other boxer. But this does not detract from the fact that boxing causes serious eye injuries. McLeod correctly points out that retinal detachment may present some months or years after an injury. It follows that prophylaxis should be given before an aspiring boxer receives his first blow. Who would be prepared to administer laser treatment to teenage boys when the procedure is not without complications?

The question is not whether the British Boxing Board of Control has the "courage and clout" to stage a longitudinal survey but whether vitreoretinal surgeons dare come off the fence and provide unequivocal advice to their patients: to refrain from boxing if the sport continues to permit injuries to the head. Whether their advice is heeded is then up to the individual person, who can choose between a risk of losing his sight and career, fame, and fortune. It is up to the law makers (and maybe society as a whole) to decide whether boxing is entertainment or grievous bodily harm.

By advocating a clinical trial of prophylactic laser treatment we would be condoning boxing in its present form. Are we seriously asking boxers to continue to injure each other in order to satisfy our curiosity as to whether laser photocoagulation might work?

AUSTIN LEACH JAMES MCGALLIARD MARIE HICKEY DWYER DAVID WONG

Vitreoretinal Team

St Paul's Eve Hospital,

Liverpool L $39 \mathrm{PF}$

1 McLeod D. Ocular injuries from boxing. BMF 1992;304:197. (25 January.)

2 Giovinazzo VJ, Yannuzzi LA, Sorenson JA, Delrowe DJ, Cambell EA. The ocular complications of boxing. Ophthalmology 1987;94:587-96.

3 Duane TS, ed. Clinical ophthalmologv. Vol 5. Philadelphia: Harper and Rowe, 1985:3.

AUTHOR'S REPLY, - My colleagues from Liverpool are perfectly at liberty to join the BMA on the moral high ground. Though most of the public are against banning boxing, other colleagues and I are quite comfortable sitting astride the philosophical fence. Unencumbered by self righteousness, we can thus get on with the job of patching up damaged eyes and providing objective advice to the British Boxing Board of Control. At the same time, information on the risks of boxing is given to all patients, whether previously injured or not, and each boxer is urged to stop. I imagine that most doctors are reconciled to the fact that patients don't necessarily heed their advice.

The counterpunch to my editorial' delivered by the boxing board's chief medical officer ${ }^{2}$ is as wide of the mark as his earlier assertion that ocular injuries from boxing are rare. ${ }^{3}$ The board's medical regulations are arbitrary and often unsustainable against boxers' actions for restraint of trade. Having agreed other criteria against which specialists can formulate advice on a boxer's eligibility for a professional licence, Whiteson is definitely hitting below the belt to claim that the regulations are "vigorously opposed" by those who seek to assist the board in its difficult deliberations. The challenge for the board is to establish a forum for expert debate, ${ }^{+}$rather than have its chief medical officer resort to public criticism of its advisers on radio and in the popular and medical press.

As to financing longitudinal surveys on ocular morbidity, the current arrangements for reexamining boxers must be tightened through the formulation of a comprehensive clinical protocol ${ }^{4}$ and a review of the competence of examining physicians. This would provide the core of any study, and, as now, the fighter himself must foot the bill from his purse. At the end of the day the punter should pay.

Department of Ophthalmology,

DAVID MCLEOD

Manchester M13 9WH

1 McLeod D. Ocular injuries from boxing. BMf 1992;304:197. (25 January.)

Whiteson A. Ocular injuries from boxing. BM7 1992:304:574 (29 February.)

3 Whiteson AL. Injuries in professional boxing: their treatment and prevention. Practitioner 1981;225:1053-7.

Giovinazzo VJ, Yannuzzi LA, Sorenson JA, Delrow DJ, Campbell EA. The ocular complications of boxing Ophthalmology 1987;94:587-96

\section{Accreditation after Goldstein}

SIR, - Stephen Brearley highlights the fact that the accreditation system in the United Kingdom is designed to permit specialist control within the NHS.' This ignores the healthy private sector. Private medicine is seen as the exclusive province of NHS consultants who resent any intrusion from those who are not "properly accredited."

"Junior doctors" unable to achieve a consultant post are therefore denied access to the private sector either by the refusal of insurance companie to recognise them or by medical advisory committees of private sector hospitals, which contro admitting rights. As a result they live in a limbo of insecurity, lurching from one locum job to another. In the past many were foreigners. Now an increasing number of home graduates are affected, and the degree of disillusionment, disappointment, and sheer misery has to be seen to be appreciated. In the past they were able either to seek employment abroad or go into general practice, but the increased requirements and restrictions in every branch of our profession has made even that an impossibility.

The argument that quality of care has to be maintained and that only the NHS can provide such standards is untenable, particularly in central London, where private general practitioners demand the very best care and are able to select a specialist at will

If practitioners wish to become specialists they should be able to do so after a reasonable period of training culminating with the EEC form of accreditation. If they then wish to continue to work in the NHS it is up to them to pursue the requirements laid down by the NHS. They should not be denied the right to practice their trade freely in the private sector or even to compete for work in the new trust system where it involves the private sector. I for one would welcome an ongoing audit or assessment programme in both the NHS and the private sector as a means of judging the continuing ability of a specialist to practice, rather than the present archaic system of apprenticeship and patronage that has outlived its usefulness and should be relegated to history.

CHARLES A AKLE

London WIN $1 \mathrm{AF}$

1 Brearley S. Accreditation after Goldstein. BMF 1992;304:518-9. 29 February.)

SIR,-Stephen Brearley correctly identifies the problems with the present accreditation system but hesitates to prescribe the necessary cathartic. The recent court ruling is a timely warning to the medical profession to reconsider the principles underlying accreditation and not merely tinker with existing procedures

The medical profession regulates its own standards of practice under an established compact with society, an arrangement beneficial to both. Higher specialist training is but a facet of this self regulation. The purpose of regulation is to ensure that specialist doctors in independent practice have attained the standards of knowledge, skill, and judgment necessary to deliver safe and effective medical care. The body responsible for ensuring this should have no consideration other than that of competence when deciding whether a doctor should be accredited. In particular, attempts to regulate the number of specialists by restricting accreditation to a set quota is not only against natural justice but tantamount to running a closed shop.

With private practice becoming increasingly lucrative for specialist doctors such restrictive practices will be resented not only by those who fal outside the quota but by paying customers who are denied a choice of specialists. If the profession does not remedy this serious deficiency it is only a matter of time before society, be it through legislation, judicial review, or an inquiry by the Monopolies and Restrictive Trade Practices Commission, forces it on us. Brewers, miners, and engine drivers have felt the heat of public wrath before, and middle class professions are not immune to it.

It is perplexing that, in these days when central planning has fallen into disrepute, professional organisations still consider themselves competent to predict the number of specialists needed in the future. Such crystal ball gazing is unlikely to be useful given that technological advances can unpredictably alter the practice of medicine and render such manpower planning worthless

The argument that the present system of tailoring training posts to the expected number of jobs will prevent disappointment to highly trained specialists unable to secure suitable employment smack of big brother trying to direct people's lives. Such highly qualified people do not need to be nannied. High earning members of society such as doctors who seek to escape uncertainties regarding career or employment by forming what seems to be a cartel, do so at the risk of compromising the historic compact between medicine and society.

Leeds General Infirmary

J P SEBASTIAN

Leeds LS1 3EX

1 Brearley S. Accreditation after Goldstein. BMf 1992;304:518-9. (29 February.

\section{Accreditation is linked to other issues}

SIR,-Stephen Brearley is right in his call for reform of the procedures of the higher medical committees. ' For too long the process of accreditation has been riddled with anomalies and secrecy. As he states, the first steps must include the creation of clear and consistently applied criteria for accrediting specialists in the United Kingdom and the end of the closed reference system. These changes are necessary as a direct consequence of the judgment given in the Goldstein case.

In the second part of his article, where he tackles the issues of manpower, training, and our relation to mainland Europe, however, the old attitudes and complacency of the British medical establishment are all too apparent. The idea that a British accreditation system totally separate from that of other countries in the European Community is needed and the implication that British consultants, by definition, must be superior to continental specialists do not stand up to examination. I believe that the debate that must inevitably follow the Goldstein case should result in wider reform of the training of specialists in the United Kingdom 